\title{
Transition Delay and Drag Reduction using Biomimetically Inspired Surface Waves
}

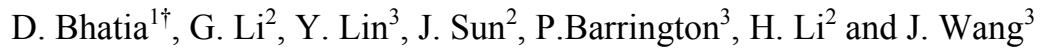 \\ ${ }^{1}$ School of Aerospace Engineering, The University of Nottingham Ningbo China, Ningbo, China 315000 \\ ${ }^{2}$ School of Aeronautics, Northwestern Polytechnical University, Xi'an, China 710072 \\ ${ }^{3}$ Faculty of Science, Engineering and Computing, Kingston University London, London, United Kingdom \\ SW15 3DW
}

†Corresponding Author Email: Dinesh.Bhatia@nottingham.edu.cn

(Received March 29, 2019; accepted December 16, 2019)

\begin{abstract}
This paper explores the use of Two-Dimensional sinusoidal surface features to delay transition and/or reduce drag. The authors, in this paper demonstrated that the presence of low amplitude sinusoidal surface features might damp the disturbances in the laminar boundary layer, reduce wall shear stress and maintain laminar flow for longer than a conventional flat plate. The hypothesis of the paper is inspired by the simplification of the dermal denticle on the surface of the shark-skin. Simulations are carried out using the Transition SST model in FLUENT based on the evidences of the transition model being suitable for a wider variety of high curvature scenarios. The surface waves are simulated for different amplitudes and wavelengths and their impact on transition onset and drag reduction are quantified at different velocities. Results presented in this paper indicate that a transition delay of $10.8 \%$ and a drag reduction of $5.2 \%$ are achievable. Furthermore, this paper adds credence to the notion that biomimicry is a very promising avenue for future drag reducing methods.
\end{abstract}

Keywords: Transition delay; Drag reduction; Surface waves; Transition SST; Shark-skin; Biomimetics.

\section{INTRODUCTION}

The conservation of energy and the reduction of carbon and nitrogen dioxide emissions are key reasons to improve the aerodynamic efficiency of aircraft. By 2050, global aviation emissions could grow by $300-700 \%$ as compared to 2005 (European Comission, 2016). To stem this staggering increase in emissions, the European Commission has targeted a $75 \%$ reduction in aviation emissions by 2050 (European Commission, 2011). Transition delay and drag reduction are few of the most promising methods to try and achieve this goal. A $10 \%$ skin friction reduction can lead to fuel savings of $\$ 250$ million/year and corresponding emission reductions for the aviation sector (Walsh, Sellers III and McGinley, 1989). However, conventional drag reduction methods have been researched extensively and have plateaued in terms of significant reductions in drag (Bushnell, 2003). There is an urgent need to look at alternate methods for drag reduction. This paper aims to demonstrate the potential of using a low amplitude biomimetically inspired wavy plate to delay transition and reduce drag.
The concept of using a wavy plate finds its inception in nature. Nature has often inspired researchers to solve technical challenges by reverse engineering natural examples. One such example is the shark and its relatively low drag while swimming. A study of the shark shows that the skin of sharks, shown in Fig. 1, (and other elasmobranch fishes such as skates, rays, etc.) possess the following features (Lang et al. 2008):

- Longitudinal riblets with a spacing of 30-100 $\mu \mathrm{m}$ from each other

- Micro-features such as dermal denticles (minute placoid scales on the skin) with 0.2-0.5 $\mu \mathrm{m}$ amplitude

- Mucous layer

- Compliant surface

The presence of the riblet, denticles and the mucous layer perform a critical function for the shark. The presence of these features on the surface of the sharkskin not only enable sharks to swim with minimum drag and catch prey but also promote anti-fouling 

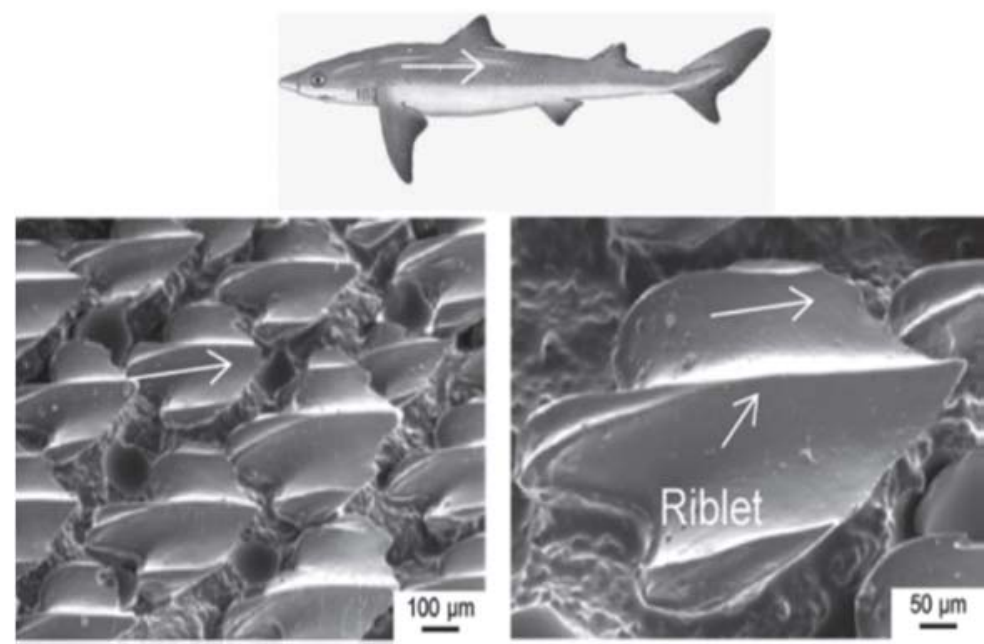

Fig. 1. Dermal denticles/Scales shown on the left and Longitudinal ridges/riblets as seen on the surface of the shark-skin which can be deemed to be micro-features (Bixler and Bhushan, 2013). Reproduced with permission from Advanced Functional Materials 23, 36 (2013). Copyright 2013 John Wiley and Sons.

behaviour (Bechert et al. 2000; Schumacher et al. 2007; Bixler and Bhushan, 2013). Studies have also shown that the live shark-skin has much lower drag than a dead one (Bechert and Hage, 2006). The live shark-skin also reacts to the incoming flow condition and changes the orientations and directions of the micro features on its skin based on flow speed etc. As such, it can be described to be a compliant surface that changes surface features based on interaction with the incoming flow. Thus, it can be concluded that the compliant shark-skin is not smooth and possesses micro-features such as dermal denticles/scales and riblets, which alternate to be compliant with the flow conditions.

The first shark skin feature i.e. the riblet based has been the inspiration for drag reduction since the last 30 years. A detailed review of riblet based geometries and their implementation has been presented in great detail by Dean and Bhushan (Dean and Bhushan, 2010). Biomimicking of riblet based geometries have also found their way into commercial applications such as the Speedo FSII swimsuit which incorporates shark-skin like microfeatures. Testing of this swimsuit demonstrated a drag reduction of $7.7 \%$ under most conditions and $10-15 \%$ when compared to normal swimsuits under stiff-body conditions (Oeffner and Lauder, 2012).

The mechanism of drag reduction through riblets is primarily explained using two different schools of thought. The first school of thought is that there is a skin-friction reduction in the valley of the riblet and this reduction is sufficient to overcome the skinfriction increase at the riblet tip thereby resulting in a net decrease in skin-friction (Choi, Moin and Kim, 1993). Will this drag reduction affect flow transition? The more popular school of thought indicates that the riblets provide resistance to the cross-flow motion and reduce the momentum transport (Bacher and Smith, 1985; Bechert et al. 1986; Luchini, Manzo and Pozzi, 1991). The mechanism has been well explained by Bixler and Bhushan (Bixler and Bhushan, 2013). They believe that within the turbulent boundary layer, with the use of optimised riblets, the vortices that are usually present on the surface of a flat plate are lifted above the surface of the riblets and pinned at the tip of these riblets. Pinning is the primary mechanism to reduce cross-stream fluid motion and also results in a reduction of momentum transfer due to the ejection of vortices from the laminar sub-viscous layer. The flow structure illustrated in Fig. 2 shows that the scale of the vortex decreases appreciably with the use of riblets but also moves away from the surface into the flow stream.
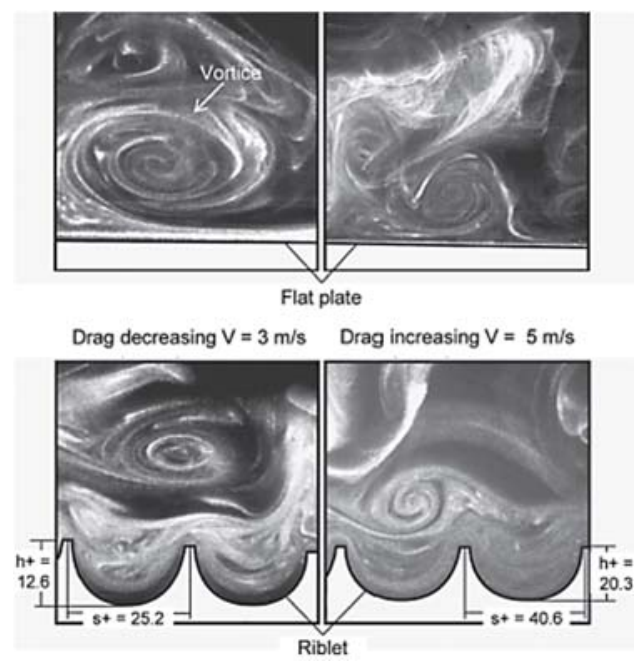

Fig. 2. Visualisation of drag reducing mechanism of riblets as explained by Bixler and Bhushan (Bixler and Bhushan, 2013). Reproduced with permission from Advanced Functional Materials 23, 36 (2013). Copyright 2013 John Wiley and Sons. 
While, the mechanism of drag reduction using riblets has been greatly studied and presented in the discussion earlier, riblet based drag reduction mechanisms focus only on drag reduction within the turbulent boundary layer.

A visualisation of the second shark-skin surface feature i.e. the dermal denticle/scales on the surface indicates a wavy pattern (Fig. 3). This wavy pattern on the shark-skin is in the streamwise direction and forms the inspiration for this investigation.

The most obvious simplification of the complex dermal denticle based wavy pattern is the simple and predictable sinusoidal wavy pattern on the entire plate surface.

The key difference between the use of a riblet based geometry and a dermal denticle based geometry is the orientation of these surface features. Riblet based geometries are oriented longitudinally (the fluid flows parallelly along the riblet and between the riblets whereas the dermal denticle based wavy surfaces are transverse features (the fluid flows along the wavy pattern and follows the profile of the pattern up and down).

While, the use of a complete wavy surface plate is a unique and novel concept, the study of isolated surface waviness on boundary layer transition is well documented. The effects of surface waviness on T-S waves, boundary layer transition and the flow structure have been studied in great detail (Wie and Malik, 1998; Cossu and Brandt, 2002; Lin et al. 2011; Gaster, 2016).

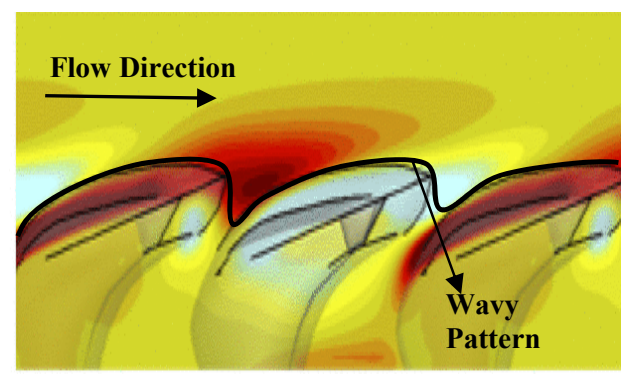

Fig. 3. Side view of the dermal denticle/scales on the surface of the shark-skin depicting a wavy pattern between denticles (Boomsma and Sotiropoulos, 2016). Reproduced with permission from Physics of Fluids 28, 3 (2016). Copyright 2016 AIP Publishing LLC.

Wie and Malik (Wie \& Malik, 1998) found that an increase in amplitude and decrease in wavelength lead to an increase in the instability of TollmienSchlichting (T-S) waves and ultimately resulted in early transition onset. Their observations correlate with other simulations conducted for surface waviness that indicated that an increase in surface wave amplitude results in a decrease of the critical Reynolds number from its Blasius value and thereby early transition onset (Lessen \& Gangwani, 1976).

Along with the amplitudes of the wave and the wavelength, the number of waves and their position were also investigated. These findings are based on a study of 1,2, 4 and 8 waves located at different positions on the plate. The transition onset location is also proportional to the wavenumber. As the wavenumber increases, the transition onset location is brought forward.

Experimental research also indicates that large amplitude waves possess vortices in the trough. Test cases which demonstrate vortices in the trough show greater amplification of disturbances resulting in early transition onset (Gaster, 2016). Other researchers have investigated different scenarios, but also focused on the vortices in the troughs (Choi, Moin and Kim, 1993; Goldstein, Handler and Sirovich, 1995). Thus, the presence of waviness leads to T-S wave amplification and thereby early transition onset.

Most existing research indicates that surface waves and geometric features are surface imperfections and bring the transition onset location forward. In all of the above-mentioned research, the surface waves have a normalised amplitude i.e. the height $h$ to boundary layer thickness $\delta$ ratio of atleast 100 times the shark-skin denticle $(h / \delta \sim 0.001-0.004)$ and therefore have a detrimental effect on the boundary layer.

However, studies also exist that make use of geometric features such as cavities and grooves to attain drag reduction of about 9.7\% (Mariotti, Buresti and Salvetti, 2014, 2015, 2019; Mariotti et al. 2017). The use of a groove by Marrioti, Buresti and Salvetti (2019) that was of $40 \%$ of the thickness of the upstream boundary layer demonstrates the potential of using a non-flat surface feature to attain drag reduction.

In this paper, the drag reduction potential of the wavy profile of a similar scale $(h / \delta \sim 0.003)$ to the dermal denticle is investigated. Whether a positive interaction between the flow and the wavy plate is possible will be investigated by studying the nearwall flow structure in the laminar boundary layer of the wavy plate. The impact of change in the amplitude and velocity are quantified at different wavenumbers.

The paper is organised in the following manner: Section 2 describes the Model, Mesh, and the Validation of the CFD setup. Section 3 provides insight into the flow structure of a single wave and results from the amplitude and velocity changes. Section 4 discusses the key parameters from the results while Section 5 summarises the key conclusions from the paper.

\section{Methodology}

Modelling and simulation of shark skin inspired micro features is challenging as it involves te accurate capture of uneven surface geometries as well as very fine and tiny features on the surface of the plate. A state of the art critical literature review based on a number of papers (Tomiyama \& Fukagata, 2013; Ma, Lu \& Tryggvason, 2015; Tryggvason, Ma \& Lu, 2016; Gorlé et al. 2019) enabled the authors to carefully select a baseline 
model for simulations which were then used to introduce CFD modelling concepts. Finally, wellknown published cases were tested to validate authors' results in order to demonstrate the ability of CFD on predicting transitions over surfaces with curvature and wavy features.

\subsection{Sample Models}

A flat plate with a smooth surface is selected as the baseline model. The flat plate consists of a quarterelliptical leading edge with an aspect ratio of 12 . The dimensions of the plate are $1.8 \mathrm{~m}$ long (excluding the leading edge, $0.072 \mathrm{~m}$ ) and a thickness of $0.006 \mathrm{~m}$ (Fig. 4 a). This represents the classic scenario with experimental and simulation results in the literatures.

The effects of a wavy surface on flow transition were studied by incorporating a sinusoidal wavy surface feature on top of the flat plate (Fig. $4 \mathrm{~b}$ ). The only difference between the two plates is the profiles of the top surfaces. The wavenumbers and amplitudes are altered in each individual test case as described in following sections. Both plates were placed along the flow direction, as shown in Fig. 4.

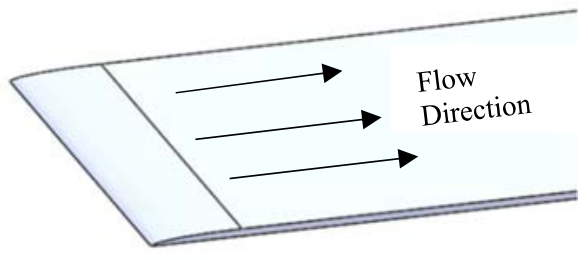

a) Flat plate

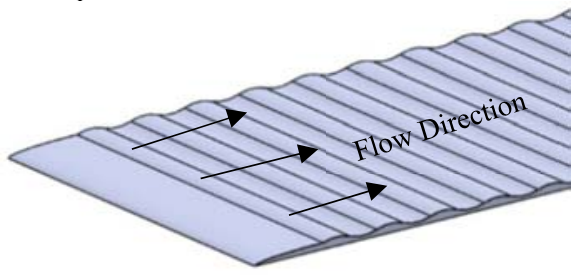

b) Wavy Plate

Fig. 4. 3D representation of a) the 2D flat plate,

b) $2 \mathrm{D}$ wavy plate. In both cases, the plate is oriented in the streamwise direction.

\subsection{CFD Model: Mesh Generations and Solver Settings}

ANSYS Fluent is chosen as the CFD package for this study. A structured multi-block mesh that is clustered around the leading edge is used. The velocity inlet is placed at $20 t$ (where $t$ is the thickness of the plate) from the leading edge of the plate to ensure the flow is well developed at the leading edge. The height of the domain is maintained at $25 t$ and extends $80 t$ downstream from the trailing edge.

A maximum wall $y+$ value of 0.1 is maintained throughout the mesh, and the wall normal expansion ratio is set to 1.07 . A mesh with $400 \mathrm{k}$ elements was chosen for the simulation based on grid independence studies as well as to ensure a required resolution of micro features.
Table 1 Grid independence study based on the transition onset Reynolds number

\begin{tabular}{|c|c|}
\hline Node Count & $\begin{array}{c}\text { Transition Reynolds } \\
\text { Number }\left(R e_{t r}\right)\end{array}$ \\
\hline $1.8 \times 10^{5}$ & $2.73 \times 10^{6}$ \\
\hline $4 \times 10^{5}$ & $2.82 \times 10^{6}$ \\
\hline $1 \times 10^{6}$ & $2.823 \times 10^{6}$ \\
\hline
\end{tabular}

The mesh possesses a no-slip wall boundary condition for the flat plate along with a velocity inlet and a pressure outlet at the far-right of the domain. All other planes of the domain have a symmetry boundary (Fig. 5).

The Transition SST model in Fluent is used for the simulation. Based on existing literature, the solver settings are as follows (Menter et al. 2005, 2006; Langtry et al. 2006; Lin et al. 2011):

- Steady state pressure based solver with absolute velocity formulation

- Transition SST model with the diffusion coefficient $\boldsymbol{\sigma}_{\boldsymbol{\theta} \boldsymbol{t}}=\mathbf{1 0}$

- Second order upwind SIMPLE scheme for pressure, momentum and the turbulence equations and Least Square Cell based method for the gradient

- The under-relaxation factors are reduced to ensure stable convergence of the simulation

- Velocity is set to $50.1 \mathrm{~ms}^{-1}$ and Turbulence Intensity $(\mathrm{Tu})$ of $0.18 \%$ at the leading edge

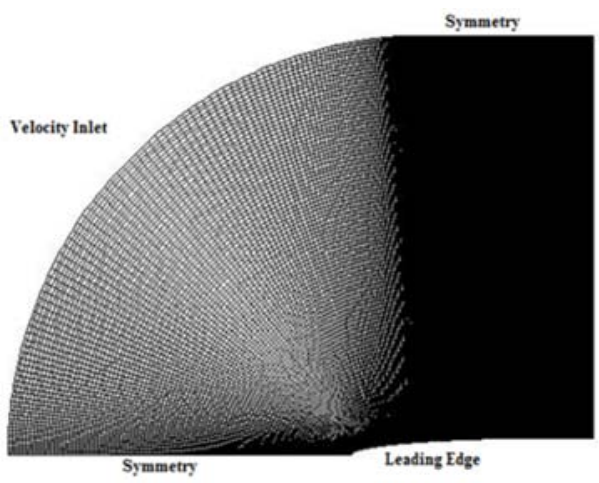

Fig. 5. Structured Multi-Block Mesh clustered around the leading edge with a total node count of $400 \mathrm{k}$.

\subsection{Validation of Modelling Techniques and Reliability of the Simulations}

The Transition SST model has been developed and calibrated using experimental test cases based on flat plates and turbine blades. The Transition SST model has demonstrated reliable capturing of the flow phenomenon and transition onset location in a variety of cases including flat plates, aerofoils and turbine blades with varying curvatures (Menter et al. 2005).

In this study, the Transition SST model is initially used to obtain the classical 2D benchmarking results and validate the flow conditions for the flat plate. 
Results are compared to existing data (Menter et al. 2006; Lin et al. 2011).

The benchmarking results (Fig. 6) show the skin friction coefficient of fluid flow $C_{f}$ vs. the local Reynolds number $R e_{x}$ over the flat plate. The black line represents the simulation results of the authors, the green points are the results presented by Menter using CFX, the violet points depict the experimental transition onset position of the Schubauer Klebanoff TSK experiment, and the red points indicates the benchmark results as conducted by Lin et al. Fig. 6 shows that the curve for $C_{f}$ vs. $R e_{x}$ in the authors' case is in close accordance with the experimental transition onset location as well as the results presented by Lin et al.

To ensure accurate capture of the flow mechanism on the wavy plate as well as to tune parameters in order to get correct resolutions for the geometries of the models with micro features, a published case scenario of a plate with one wave surface feature was selected for validation (Lin et al. 2011). The wavy feature is located at $x / L=0.2$ from the leading edge, has an amplitude of $h / \delta=0.4$ and a wavelength of $1 / 18^{t h}$ the length of the plate. The skin friction coefficients obtained from the simulation are compared to the ones obtained by Lin et al. The results demonstrate that the skin friction values are comparable in both the cases. The simulation conducted by the authors, together with the model setup and mesh generated could accurately reflects the presence of the wavy feature at a Reynolds number of about $1 \times 10^{6}$.

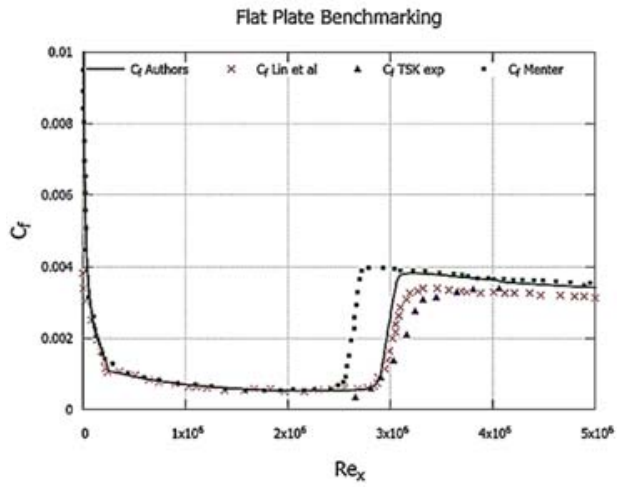

Fig. 6. Flat Plate Benchmarking and model validation for the flat plate against existing test and simulation cases.

In addition, the capture of vortex in the trough (shown in Fig. 8) is consistent with findings by Gaster (Gaster, 2016) at a similar wavelength and amplitude. The generation of vortex is one of the primary reasons for earlier transition onset as discussed in Section 1.

Existing literature (Menter et al. 2006; Lin et al. 2011) as well as the benchmarked waviness case clearly demonstrate the suitability of the Transition SST model for prediction of transition onset for high curvature, non-flat and wavy geometries. Comparison with existing experimental data (Gaster, 2016) is a clear indicator that the current mesh and simulation model can accurately capture the flow mechanism in the case of a plate with a wavy feature and is therefore a reliable simulation setup for this research. The use of a 2D model for transition prediction conforms to existing transition onset prediction cases that use the Transition SST model to predict transition onset in a variety of $2 \mathrm{D}$ cases (Menter et al. 2006; Lin et al. 2011).

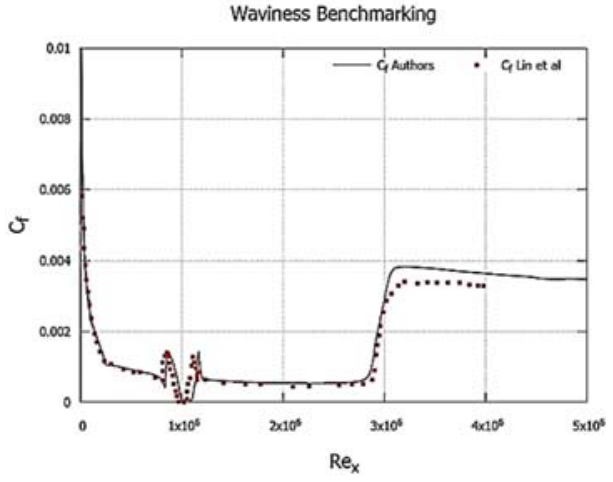

Fig. 7. Waviness benchmarking and model validation using a single wave test case.

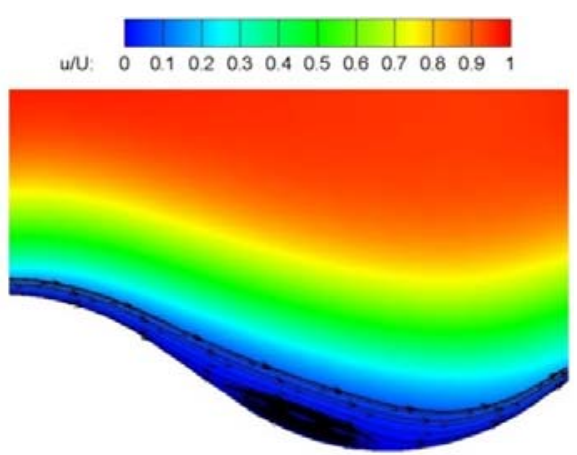

Fig. 8. Vortex captured in the trough.

\section{RESUlts}

In this section, results are presented in three sections following a natural logical order mainly to report findings of our research rather than conducting optimisation. In 3.1, three amplitudes are presented that demonstrate transition delay and drag reduction. In 3.2, interesting phenomena are first illustrated in classical plots such as velocity profiles and pressure coefficient $C_{p}$. The transition performance of wavy plate is then compared with that of the flat plate. Following this, a detailed and closer investigation of flow behaviours over single of wave is carried out. Section 3.3 presents results for boundary layer transition variations with velocity at different wavenumbers. This is to demonstrate that changes of flow condition, such as velocity, may require adaptive alterations of wavenumber and/or amplitude to achieve transition delay.

\subsection{Transition Delay at Varying Amplitudes and Wavenumbers}

The impact of changes in amplitude of the surface 


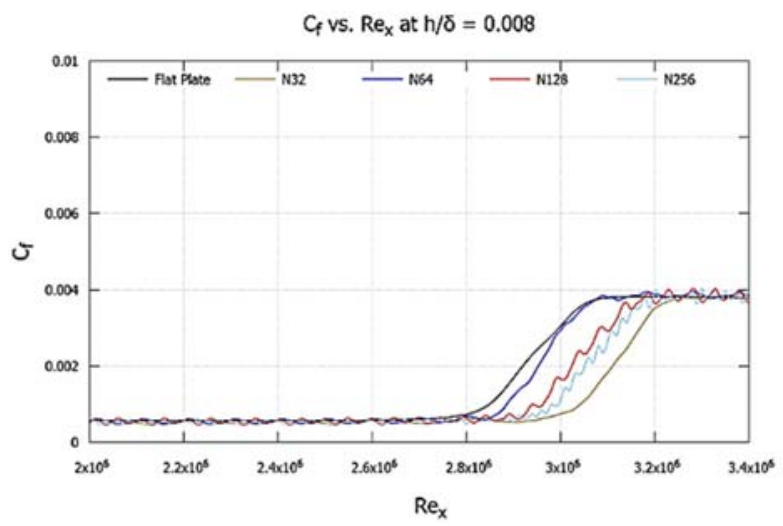

Fig. 9. Skin friction coefficients for different wavenumbers plotted against the local Reynolds number at an amplitude of $h / \delta=0.008$.

waves on boundary layer transition are quantified at a fixed flow velocity of $50.1 \mathrm{~m} / \mathrm{s}$. The simulation cases were selected based on the $(h / \delta)$ ratio (

Table 2). Each amplitude is studied at four different wavenumbers viz. $32,64,128$ and 256 waves. Results are analysed by plotting the skin friction coefficient, the normalised velocity contours and the total drag. The wave amplitude is reduced sequentially and all amplitudes are lesser than the layer depicting the region of very low velocity in the laminar boundary layer (upto $u / U=0.3$ ).

For all results in this section, the boundary layer thickness $\delta$ for all the wavy cases are measured at the point at the end point of the laminar boundary layer. The contour plots are normalised by using the height of the domain as Y.

Table 2 Allocation of wavy plate test cases based on changes in the $(h / \delta)$ ratio at velocity $50.1 \mathrm{~m} / \mathrm{s}$

\begin{tabular}{|c|c|c|c|}
\hline Wavenumber (N) & \multicolumn{3}{|c|}{ Amplitude $(h / \delta)$} \\
\cline { 1 - 1 } 32 & \multirow{3}{*}{0.008} & 0.004 & \multirow{2}{*}{0.003} \\
\cline { 1 - 1 } 64 & & & \\
\cline { 1 - 1 } 256 & & & \\
\cline { 1 - 1 } & &
\end{tabular}

Table 3 Transition delay and computed drag values for different wavenumbers at $h / \delta=$ 0.008

\begin{tabular}{|c|c|c|}
\hline $\begin{array}{c}\text { Wave Number } \\
(\mathrm{N})\end{array}$ & $\begin{array}{c}\text { Transition Delay } \\
(\%)\end{array}$ & $\begin{array}{c}\text { Drag Reduction } \\
\%\end{array}$ \\
\hline 0 & 0 & 0 \\
\hline 32 & 6.71 & 2.32 \\
\hline 64 & 1.06 & -0.87 \\
\hline 128 & 4.59 & 2.09 \\
\hline 256 & 5.65 & 2.94 \\
\hline
\end{tabular}

\section{$\mathbf{h} / \boldsymbol{\delta}=\mathbf{0 . 0 0 8}$}

For $\mathrm{h} / \delta=0.008$, the $C_{f}$ vs. $R e_{x}$ plot (Fig. 9) indicates that $\mathrm{N} 32$ (32 waves) has the largest transition delay of approximately $6.71 \%$. N64 (64 waves) shows the least transition delay of $1.06 \%$.

However, as transition delay is observed in all cases, it can be assumed that the presence of low amplitude surface waves influences the flow structure in a positive manner. The maximum skin friction at the crest for all wavenumbers is up to $3 \%$ higher than the skin friction of the flat plate in the laminar region. The trough skin friction values for all wavenumbers are $25 \%$ lesser than those of the flat plate resulting in a net reduction in skin friction.

The computed drag values and the transition delay (Table 3) show that the transition delay is highest but drag reduction is the second lowest for N32. The N64 causes the overall drag to increase by $0.87 \%$. The highest overall drag reduction is produced by N256.

The velocity contours (Fig. 10) show negligible fluctuation at the boundary layer edge which indicate that the presence of the wavy plate has limited impact on the boundary layer edge.

\section{$\mathbf{h} / \delta=0.004$}

When $h / \delta$ is further reduced to 0.004 (amplitude similar to the shark-skin denticle), N256 shows a maximum transition delay of $5.3 \%$ as compared to the flat plate. However, when the results of transition delay for $\mathrm{N} 256$ at $h / \delta=0.004$ are compared with the results for $\mathrm{N} 256$ at $h / \delta=0.008$, there are no significant changes, but overall drag reduction is much lesser.

Fig. 11 illustrates that all wavenumbers at this amplitude show transition delay. Within the laminar region a net skin friction reduction of $14.51 \%$ is achieved for $\mathrm{N} 32$.

The computed drag coefficients (Table 4) suggest that the presence of a 256 wave surface reduces drag by $0.59 \%$. Although the percentage of transition delay for different wavenumber varies in a nonlinear way (Table 4), the drag reduction tends to be converging towards similar values within a range of $0.54-0.59 \%$.

\section{$\mathbf{h} / \boldsymbol{\delta}=\mathbf{0 . 0 0 3}$}

Further normalised amplitude $h / \delta$ reduction to 0.003 depicts a similar trend with transition onset delay for all give wavenumbers. 


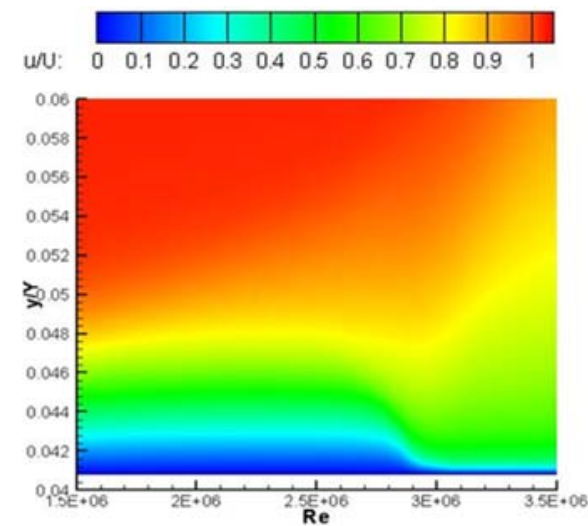

a) Flat Plate

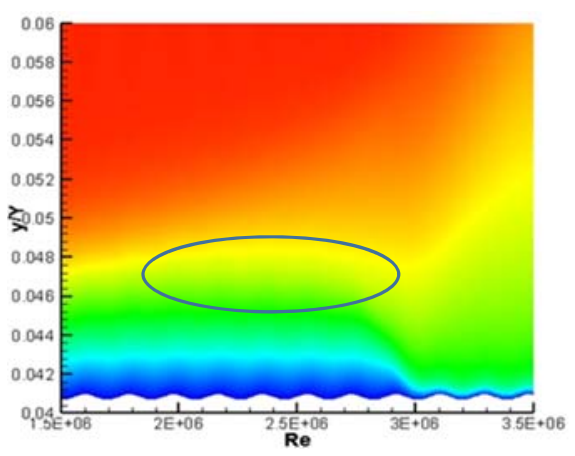

b) N32

Fig. 10. Velocity contour comparison between the flat plate (a) and N32 (b). Highlighted region shows a negligible impact of the wavy plate at the boundary layer edge in the normalised $Y$ direction.

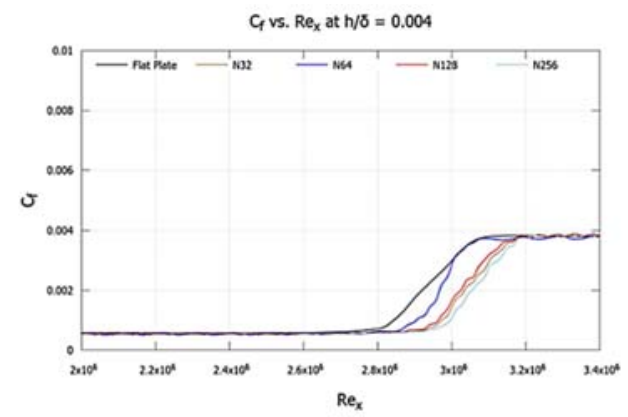

Fig. 11. Skin friction coefficients for different wavenumbers plotted against the local Reynolds number at an amplitude of $h / \delta=0.004$.

Table 4 Transition delay and computed drag values for different wavenumbers at $h / \delta=$ 0.004

\begin{tabular}{|c|c|c|}
\hline Wave Number(N) & $\begin{array}{c}\text { Transition } \\
\text { Delay (\%) }\end{array}$ & Drag Reduction \% \\
\hline 0 & 0 & 0 \\
\hline 32 & 4.80 & 0.54 \\
\hline 64 & 2.41 & 0.56 \\
\hline 128 & 3.74 & 0.58 \\
\hline 256 & 5.30 & 0.59 \\
\hline
\end{tabular}

As per Table 5, all of the cases with different wavenumbers lead to similar percentage of transition delay, but different drag reduction. The largest transition delay is $6.05 \%$ and the largest drag reduction is $0.54 \%$ for $\mathrm{N} 256$.

Table 5 Transition delay and computed drag values for different wavenumbers at $h / \delta=$ 0.003

\begin{tabular}{|c|c|c|}
\hline $\begin{array}{c}\text { Wave Number } \\
(\mathrm{N})\end{array}$ & $\begin{array}{c}\text { Transition Delay } \\
(\%)\end{array}$ & $\begin{array}{c}\text { Drag Reduction } \\
(\%)\end{array}$ \\
\hline 0 & 0 & 0 \\
\hline 32 & 5.98 & 0.18 \\
\hline 64 & 5.99 & 0.27 \\
\hline 128 & 5.8 & 0.53 \\
\hline 256 & 6.05 & 0.54 \\
\hline
\end{tabular}

\subsection{Boundary Layer Flow on Wavy Plate vs. Flat Plate}

Section 3.1 has demonstrated the effectiveness of using a wavy plate to delay transition. The boundary layer flow development and flow structure over a wavy plate is presented and analysed against a standard flat plate in this section to attain a further understanding of the impact of the wavy plate. Results in this section are provided for a 128 -wave surface with a non-dimensional amplitude of $h / \delta=$ 0.004 at the given velocity of $50.1 \mathrm{~m} / \mathrm{s}$.

The normalised velocity of wavy plate (Fig. 12b) is compared to that of the flat plate (Fig. 12a). The obvious difference between the two contours is in the region of low velocity very close to wall (up to $u / U=0.3$ ). The wavy plate possesses mild fluctuations within the low velocity layer. However, the two velocity contours depict near identical velocity distributions at the boundary layer edge.

The impacts of the wavy features on flow structure are very mild at the surface and gradually diminished while approaching to the edge of the boundary layer. The pressure coefficients for both flat plate and wavy plate are shown in Fig. 13. The orange line represents the pressure coefficient curve of flat plate where the kink indicates the transition of the flow on flat plate. The velocity fluctuation present in the velocity contour is also observed in the pressure coefficient plot (Fig. 13). The pressure coefficient plot for the wavy plate shows a kink similar to the flat plate. However, the kink for the wavy plate appears after the one for the flat plate, which indicates transition delay by utilising wavy features.

The turbulent kinetic energy (TKE) contour (Fig. 14) shows the onset of disturbance within the boundary layer for the flat plate (a) and the wavy plate (b). It can be observed that for the flat plate, the disturbance sets in earlier at about $R e_{x}=1.82 \times 10^{6}$ as opposed to about $R e_{x}=1.89 \times 10^{6}$ for wavy plate.

Transition takes place due to the amplification of these disturbances (TKE), which is associated with the tendency of the swirling of a fluid (the eddies). The early appearance of the disturbance for the flat plate could be an indicator of early transition onset 
as indicated by TKE contour plot (Fig. 14), which is visible from the velocity contour (Fig. 10) as well as the plot for the pressure coefficient (Fig. 13)

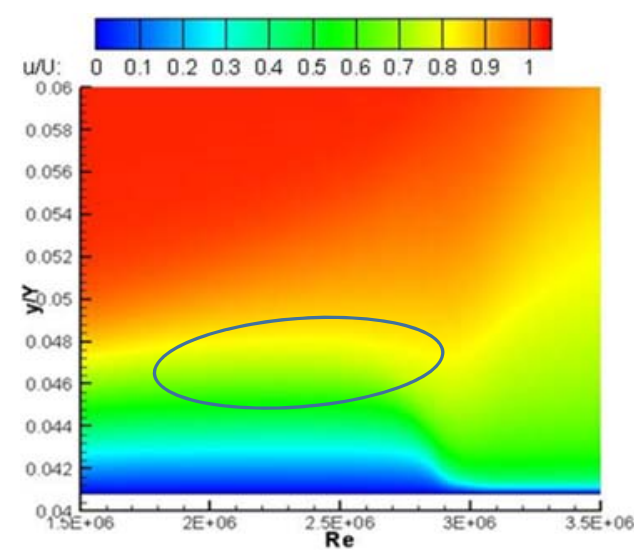

a. Flat Plate

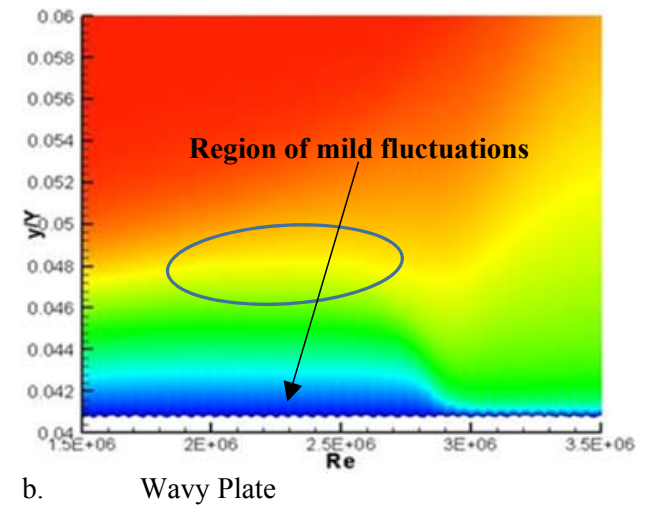

Fig. 12. Normalised Velocity Contours for the Flat Plate (a) and the Wavy Plate (b). Contours are plotted with the Local Reynolds number on the $X$ axis and the normalised $Y$ on the $Y$ axis.

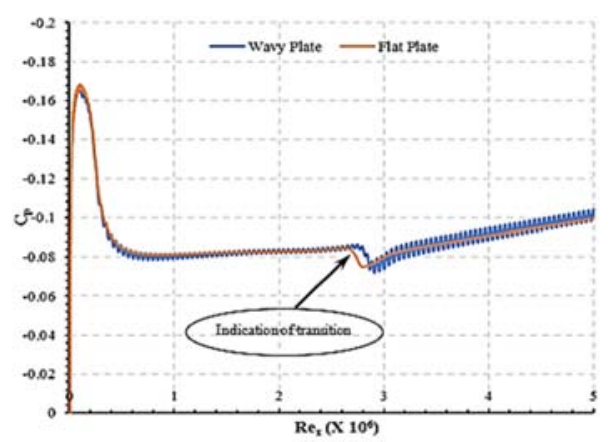

Fig. 13. Pressure coefficient for the wavy plate and the flat plate plotted against the local Reynolds number.

Skin friction coefficient $\left(\mathrm{C}_{\mathrm{f}}\right)$ plotted against the local Reynolds Number $\left(\mathrm{Re}_{\mathrm{x}}\right)$ for the wavy plate and the flat plate shown in Fig. 15, confirms that flow transition over wavy plate is delayed compared to the flow transition over flat plate. The wavy features have brought positive effects to the flow in terms of delaying transition.

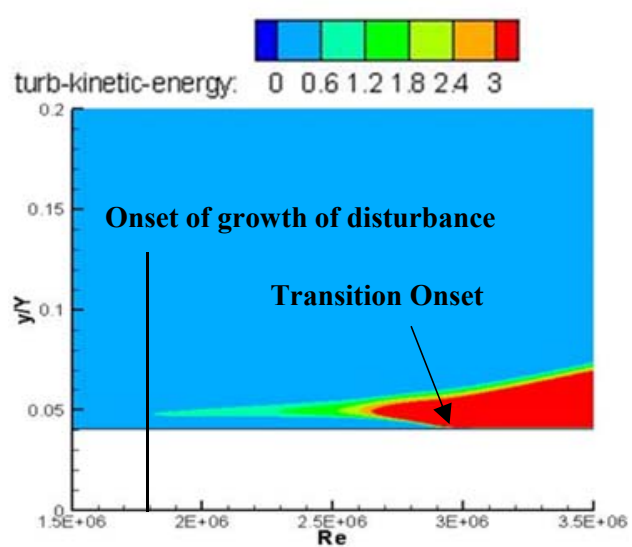

a. Flat Plate

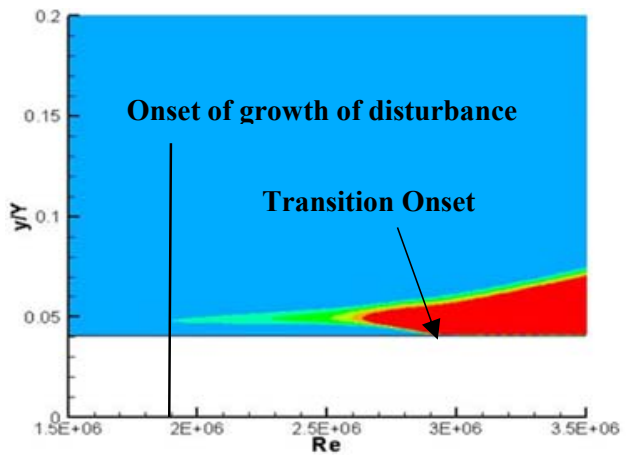

Fig. 14. TKE Contours for the Flat Plate (a) and the Wavy Plate (b). Onset of disturbance within the boundary layer is highlighted for both cases.

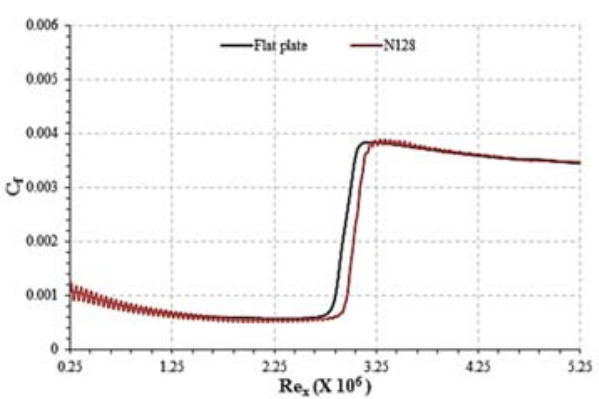

Fig. 15. Skin friction coefficient $\left(\mathrm{C}_{\mathrm{f}}\right)$ plotted against the local Reynolds Number $\left(\operatorname{Re}_{x}\right)$ for the wavy plate and the flat plate.

Fig. 15 shows that the $\mathrm{C}_{\mathrm{f}}$ varies along with the surface wavy features and reaches the higher values on the peak and then reduces to the lower ones at the troughs. In addition, trend of the $\mathrm{C}_{\mathrm{f}}$ follows the same trend of the $\mathrm{C}_{\mathrm{f}}$ for flat plate. After $\mathrm{Re}_{\mathrm{x}}$ is greater than $1.65 \times 10^{6}$, it appears that the values of $C_{f}$ for wavy plate becomes less than the values of $\mathrm{C}_{\mathrm{f}}$ for flat plat even at the crest peak. More detailed friction coefficient curves $\mathrm{C}_{\mathrm{f}}$ up to transition region for flat plate and wavy plate are plotted in Fig. 16. 


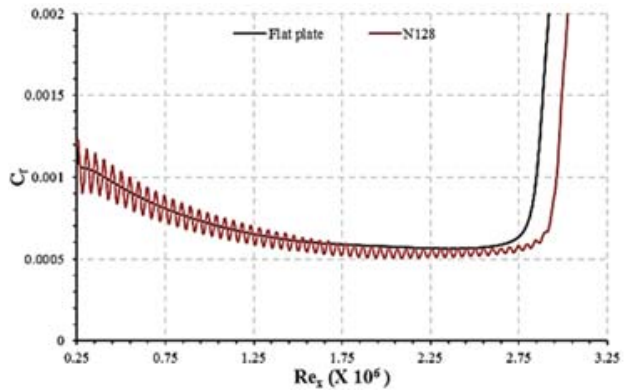

a. Cumulative skin friction

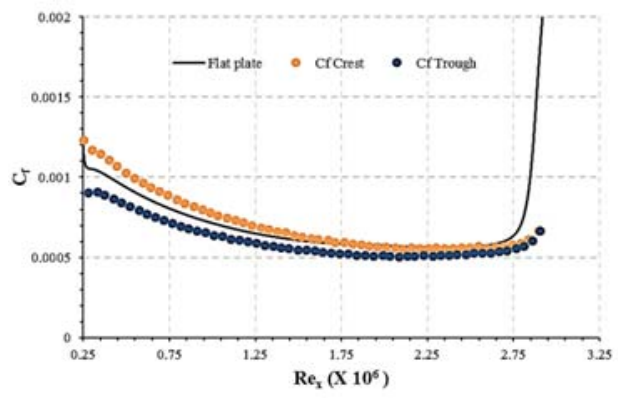

b. Individual crest and trough skin friction

Fig. 16. Skin friction coefficient $\left(C_{f}\right)$ plotted against the local Reynolds Number $\left(\operatorname{Re}_{x}\right)$ for the wavy plate and the flat plate up to the transition point of wavy plate. (a) The cumulative skin friction coefficient for the wavy plate vs. the flat plate. (b) Skin Friction coefficient at each crest and trough of the wavy plate as compared to the flat plate.

The presence of the wavy plate not only highlights the fluctuations close to the wall but also has a pronounced effect on the transition onset compared to the flat plate (Fig. 16 a). Transition onset is delayed by $4.8 \%$. The skin friction coefficient at the crest of the wave is initially higher than that of flat plate in the laminar region and steadily reduces along the length of the wavy plate (Fig. 16 b). At about $R e_{x}=1.75 \times 10^{6}$, the skin friction coefficient at the crest is equal to that of the flat plate thereafter reducing to a value below that of the flat plate (Fig. $16 \mathrm{~b})$. The skin friction at the crest in the laminar region is calculated to be on an average $1.25 \%$ higher than that of the flat plate. The skin friction at the trough is always lower than that of the flat plate by an average of $15.76 \%$. The net skin friction deficit for the wavy plate is calculated at $14.51 \%$, which might be the reason causing the transition delay.

This deficit in skin friction and transition delay influences the drag as well. The computed Cd values indicate that the drag in the laminar boundary layer is $1.72 \%$ lower for the wavy plate and $0.6 \%$ lower than the flat plate over the entire length of the plate. During the FP7 project-SANAD (Synthesis of Advanced top Nano-coatings with improved Aerodynamic and De-icing behaviour, Marie Curie Actions - Industry-Academia Partnerships and Pathways (IAPP), project 324443), British Airways has advised the authors that $0.4 \%$ drag reduction will make a significant difference to the fuel consumption and costs. Therefore, we may conclude that the micro- surface features with waviness may have significant potential for viscous drag reduction over aircraft body.

Thus, on a macro level the presence of the wavy features has an impact close to the wall, can lead to transition delay and drag reduction. The reasons for the transition delay and drag reduction might be understood by further analysing the flow structure close to the wall on a micro-level.

The micro-level analysis of the flow structure is conducted by exploring the underlying mechanisms of the drag reduction effect on the wavy plate. The boundary layer flow development on the wavy plate is presented by the normalised velocity distribution over the crest and the trough presented in Fig. 19. A series of extraction points are identified along a single wave as shown in Fig. 17. The first 5 points from left to right A-E correspond to the crest surface and the following 5 points E-I correspond to the trough surface. The last two points $\mathrm{J}$ and $\mathrm{K}$ are supplementary points.

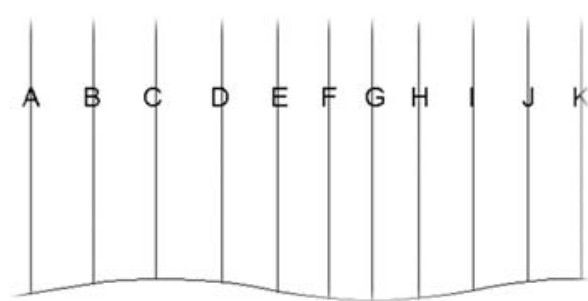

Fig. 17. Data extraction points along a single wave. Data is extracted at 5 points along the crest (A-E) and 5 points along the trough (E-I). $\mathrm{J}-\mathrm{K}$ are supplementary points.

The boundary layer velocity profiles along the crest and the trough over a single wave are presented in Fig. 18. The single wave is located within the laminar boundary layer zone and the point $\mathrm{A}$ is at $x / L=0.4$. Non-dimensional velocity (normalized by freestream inlet velocity) is plotted against normalised distance away from the surface (normalized by the boundary layer thickness on the flat plate). The velocity profiles are presented as groups of first crest rising (point AC, Fig. 18 a), crest falling (point C-G, Fig. 18 b), second rising (point G-K, Fig. $18 \mathrm{c}$ ). Finally the comparison of the velocity profiles for points $\mathrm{A}, \mathrm{E}$, and $\mathrm{I}$, which are the points at zero, half and one wavelength (Fig. $18 \mathrm{~d}$ ) and the comparison of the velocity profiles for two crest peak points $\mathrm{C}$ and $\mathrm{K}$ (Fig. 18 e) are presented. A comparison of the corresponding points on the flat plate and the wavy plate are presented (Fig. 18 f). Point C' corresponds to the same $\mathrm{x}$ location as that of Point $\mathrm{C}$ on the wave. Similarly, Point G' corresponds to the same $x$ location as that of Point $\mathrm{G}$ on the wave.

For the single wave, the gradient of velocity at the wall are compared and analysed. As the wave rises towards the crest peak (Fig. 18 a), the gradient of velocity at the wall becomes steeper although it is unclear that the flow at point $\mathrm{C}$ is more turbulent or 


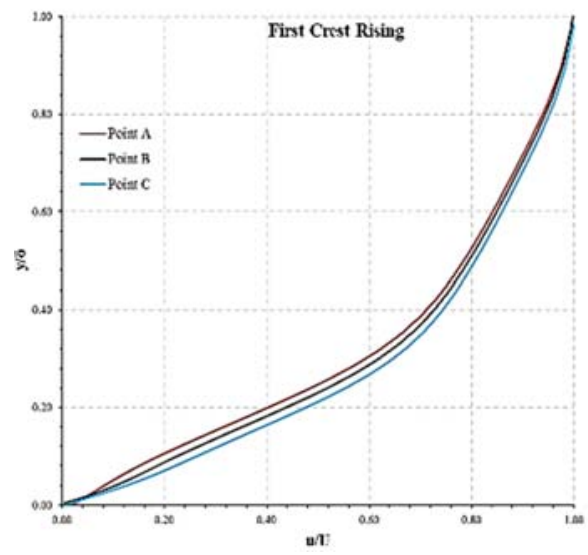

(a)

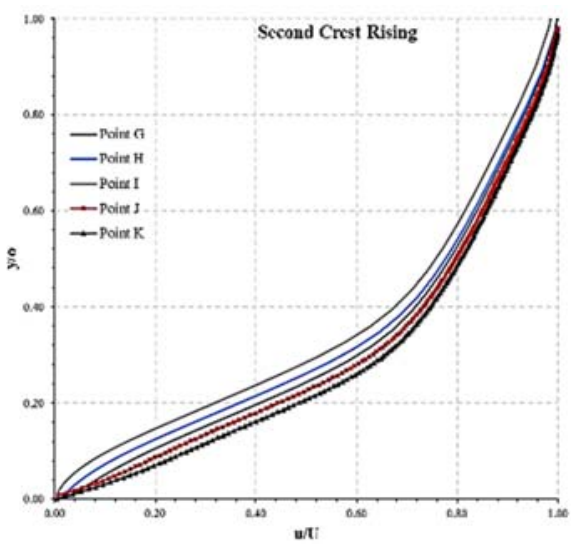

(b)

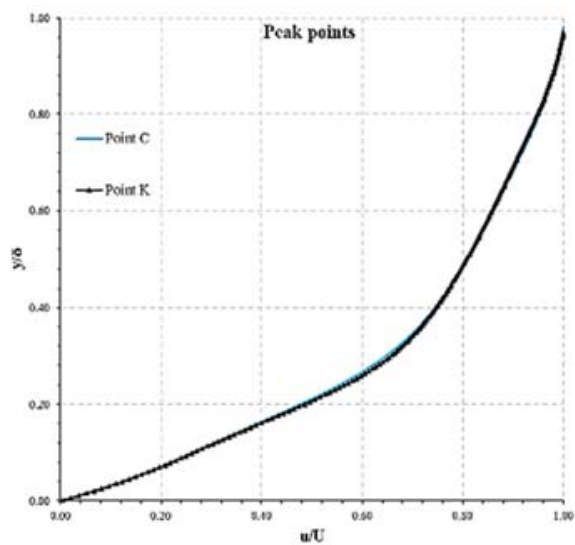

(e)

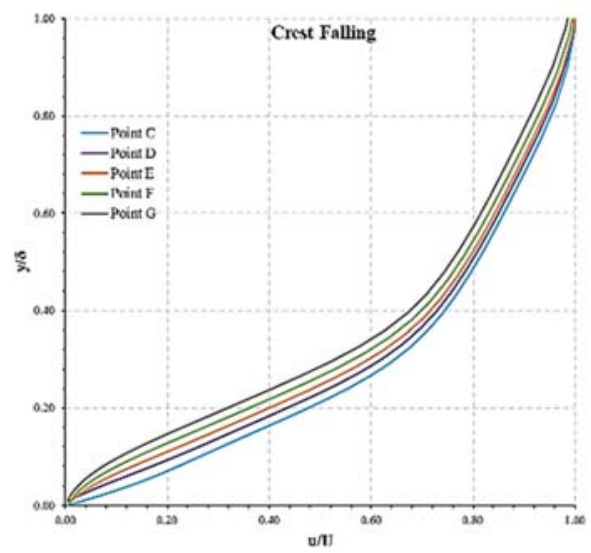

(b)

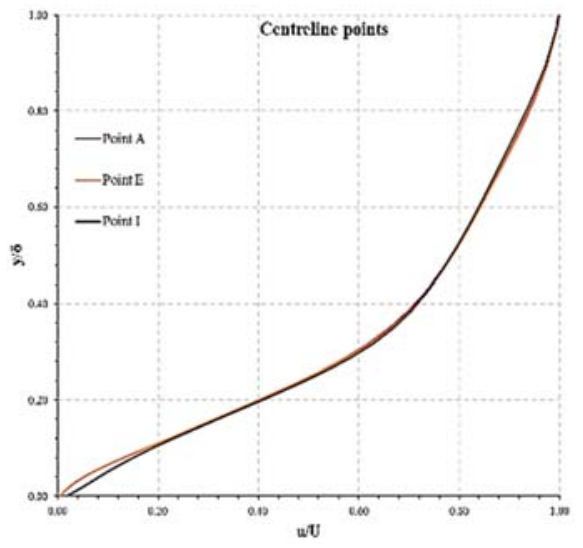

(d)

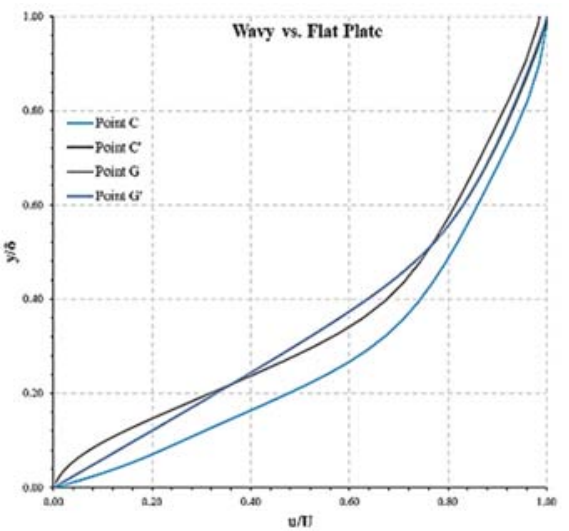

(f)

Fig. 18. Velocity profiles over a single wave. (a) The first crest rise from Point $A$ to $C$ and (b) the crest falling from point $C$ to $G$. (c) the second crest rise from point $G$ to $K$. (d) the data at the wave centreline points. (e) the peak points of the waves and (f) comparison between wavy plate and corresponding points on the flat plate named as Point $C^{\prime}$ and $G^{\prime}$ respectively.

possesses more turbulent viscosity. When going downhill from point $\mathrm{C}$ to $\mathrm{G}$ (Fig. 18 b), velocity gradient at the wall reverses back and become flatter. The velocity gradient at the crest peak (point $\mathrm{C}$ ) is the largest, while the velocity gradient at the bottom (point $\mathrm{G}$ ) is the smallest.
After the lowest point on the sinusoidal curve (point $\mathrm{G}$ ) has been reached, the curve starts to rise again from point $\mathrm{G}$ to $\mathrm{K}$. In Fig. $18 \mathrm{c}$, the velocity gradient increases from Point $G$ to Point $K$ and from the lowest value at point $G$ to the highest value at $\mathrm{K}$. As expected, the comparison of the velocity 
gradients at point A, E (half wavelength) and I (one wavelength) (Fig. $18 \mathrm{~d}$ ) indicates that the velocity gradients for point A, E, and I are similar to each other. In addition, Fig. 18 e confirmed the similarity of the velocity gradient at points $\mathrm{C}$ and $\mathrm{K}$, which are the two crest-peak points. Fig. 18, in general confirmed that velocity gradients at point $\mathrm{C}$ and $\mathrm{G}$ are the two extremes, highest and lowest in values. That is, as the flow goes through a wavelength, the velocity gradient changes between the highest value (at the top of the crest) and the lowest value at the bottom of the trough. Furthermore, the ratio of normalised velocities for wavy plate and flat plate at the same point were calculated. The ratio of normalised velocity to that of the flat plate at point $\mathrm{A}$ is 0.98 , at point $\mathrm{E}, 0.85$ and at point $\mathrm{I} 0.92$, indicating that the normalised velocity for wavy plate at those points is lower than that of the flat plate. The normalised velocity gradient at the centreline points (points A, E and I) for the sinusoidal wave indicates that the presence of the adverse gradient (crest rising) does not adversely affect the flow whereas the presence of a favourable gradient enhances the flow characteristics.

A comparison of the vorticity magnitude also indicates that at points $\mathrm{A}, \mathrm{E}$ and $\mathrm{I}$, the vorticity magnitude has a constant ratio of 0.87 versus the flat plate.

Finally, a comparison of Point $\mathrm{C}$ and Point C' indicate that the presence of the crest results in a larger velocity gradient as compared to the flat plate. The gradient for Point $\mathrm{G}$ is lesser than Point G' close to the wall as well as near the edge of the boundary layer.

Normalised velocity contour and turbulent kinetic energy (TKE) distribution (Fig. 19 and Fig. 20) are plotted to better visualize the differences of the boundary layer flow between the crest and the trough sides of the wave and the differences of the actions flowing up and down hill. The contours of the normalised velocity as well as the TKE distribution provide a better insight into the transition behaviour and drag reduction effect later.

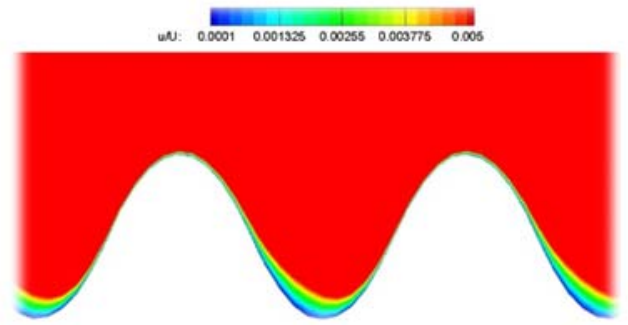

Fig. 19. Normalised velocity contour over the wavy plate.

The normalised velocity contour (Fig. 19) suggests that the velocity distribution over the crest and in the trough, are fundamentally different. The velocity distribution in the trough shows a larger region of low velocity as compared to the distribution over the crest. Although Fig. $18 \mathrm{~d}$ shows that the velocity gradients for the half wavelength periodic points are similar to each other, the velocity contour shows asymmetric distributions for flow going uphill and downhill. Observations suggest that the flow going uphill has higher velocity.

The TKE distribution over the wavy plate also shows varied levels of TKE over the crest and the trough (Fig. 20). The TKE distribution correlates with the normalised velocity contour and depicts a larger region of low turbulence in the trough as compared to the distribution over the crest. The TKE for the wavy plate follows the geometric shape of the wave. The TKE is at its highest on the crests and lowest in the trough. The TKE for the wavy plate is lesser than that for the flat plate over any given measured point.

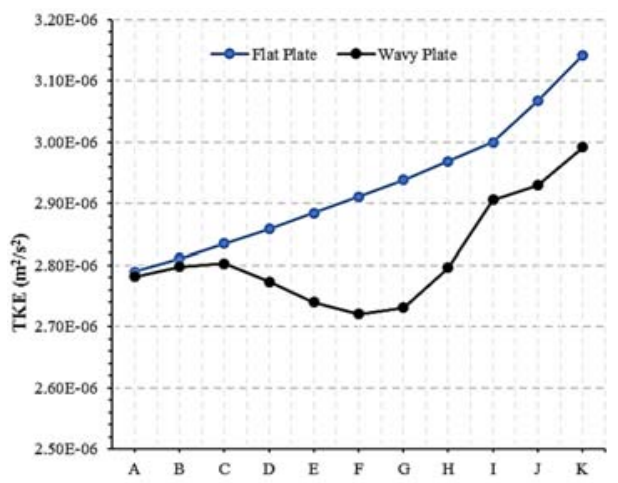

Fig. 20. Turbulent Kinetic Energy $\left(\mathrm{m}^{2} / \mathrm{s}^{2}\right)$ distribution over the wavy plate as compared to the flat plate on points $A-K$.

The results presented in this section conclusively point out that the presence of a wavy plate has a significant impact on the flow structure on a microlevel within the boundary layer. The characterising properties of the wave are its amplitude and its wavelength/wavenumber. Changes in the amplitude will impact the flow structure on a micro as well as a macro level.

\subsection{Impact of Velocity}

The impact of velocity is estimated at a given amplitude of $h / \delta=0.004$. Two different velocities (30 $\mathrm{ms}^{-1}$ and $80 \mathrm{~ms}^{-1}$ ) are compared to the given value of $50 \mathrm{~ms}^{-1}$. The velocity contours (Fig. 21) and the skin friction coefficients (Fig. 22) are plotted and transition delay is computed for different velocities.

The velocity contours (Fig. 21) suggest that at $30 \mathrm{~ms}^{-1}$ (shown in Fig. 21 a) the region of low velocity (unto $u / U=0.3$ ) is the thickest and it successively reduces as the velocity increases. As the amplitude of the wavy plate remains constant, the wavy plate penetrates further into the low velocity region of the boundary layer as the velocity is increased (shown in Fig. 21 b and c).

The skin friction coefficients (Fig. 22) indicate that transition delay is maintained at all three velocities albeit with different percentages and in different 
orders of wavenumber. As the velocity increases the transition onset Reynolds number decreases. For all wavenumbers, transition delay increases as velocity increases when compared to the flat plate. The skin friction plot (Fig. 22 a) shows that the amplitude of skin friction fluctuations increases with the increase of speed throughout the boundary layer.

UY
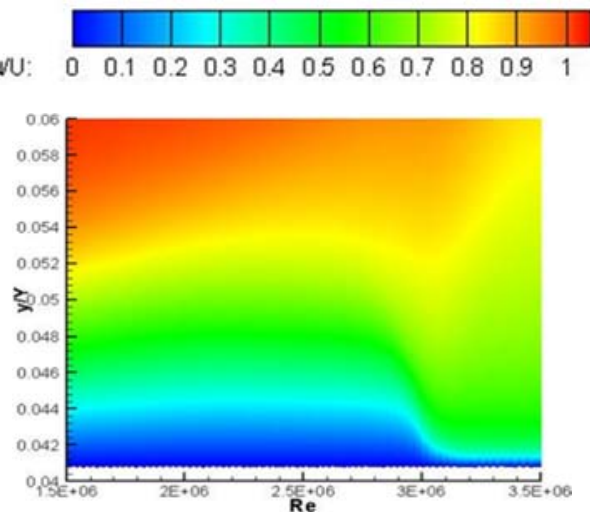

a. $30 \mathrm{~ms}^{-1}$

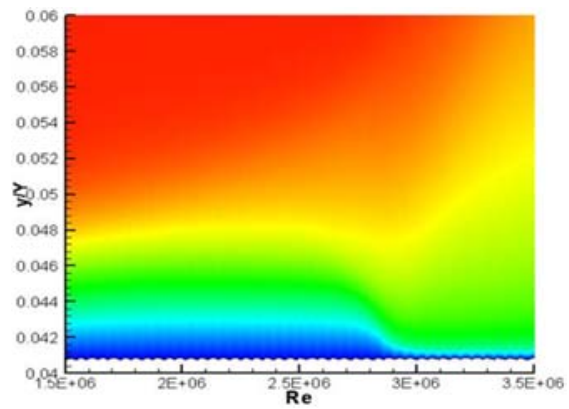

b. $\quad 50.1 \mathrm{~ms}^{-1}$

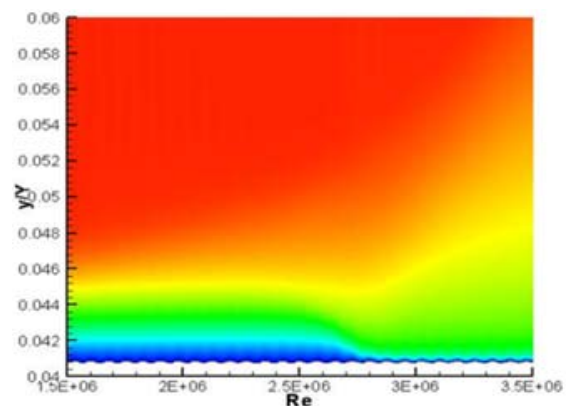

c. $80 \mathrm{~ms}^{-1}$

Fig. 21. Velocity contours comparison for three different velocities 30 ms-1 (a), 50.1 ms-1

(reproduced) (b) and $80 \mathrm{~ms}-1$ (c). N128 is used for the case comparison.

At $80 \mathrm{~ms}^{-1}$, the skin friction coefficients for all wavenumbers show a pronounced fluctuation in the turbulent boundary layer (Fig. 22 b).

The transition delay attained (Table 6) does not follow a sequential pattern, and it is maximum of $3.987 \%$ at $30 \mathrm{~ms}^{-1}$ and of $4.7 \%$ at $50.1 \mathrm{~ms}^{-1}$ both for N256 waves while it is the maximum of $10.852 \%$ for $\mathrm{N} 32$ waves at $80 \mathrm{~ms}^{-1}$. This non-sequential pattern indicates that transition delay is very condition dependent and depends on the in-flow conditions, the wavenumber and the amplitude.

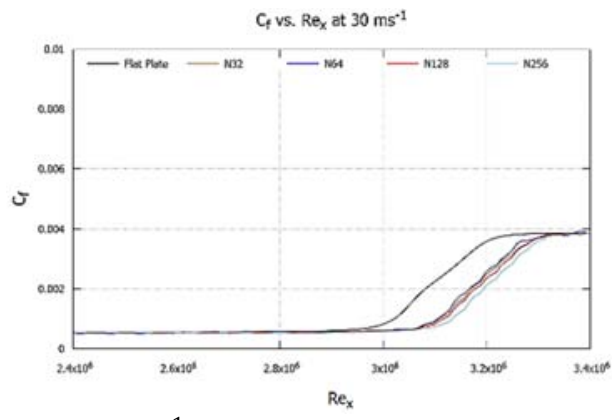

a. $\quad 30 m s^{-1}$

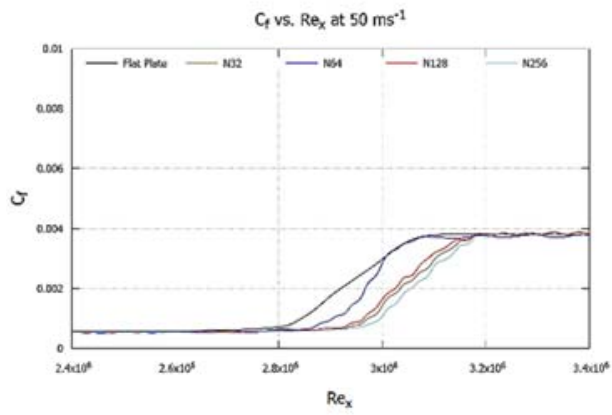

b. $50.1 \mathrm{~ms}^{-1}$

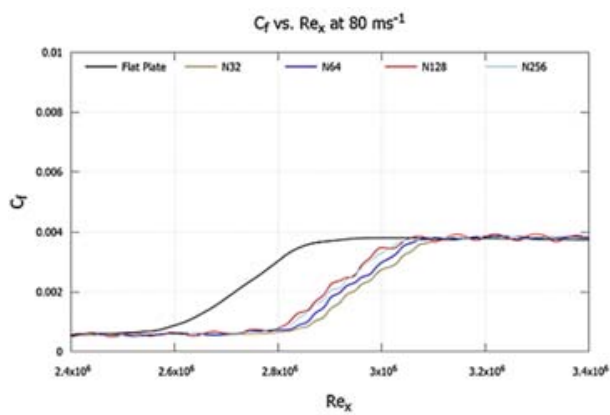

c. $80 \mathrm{~ms}^{-1}$

Fig. 22. Skin friction coefficients for different wavenumbers at $30 \mathrm{~ms}-1$ (a), $50.1 \mathrm{~ms}-1$ (b) and 80 ms-1 (c).

Table 6 Transition delay at $30 \mathrm{~ms}^{-1}, 50 \mathrm{~ms}^{-1}$ and $80 \mathrm{~ms}^{-1}$ for $h / \delta=0.004$

\begin{tabular}{|c|c|c|c|}
\hline $\begin{array}{c}\text { Wave } \\
\text { Number } \\
(\mathrm{N})\end{array}$ & $\begin{array}{c}\text { Drag } \\
\text { reduction } \\
\text { at } \\
30 \mathrm{~ms}^{-1} \\
(\%)\end{array}$ & $\begin{array}{c}\text { Drag } \\
\text { reduction at } \\
50.1 \mathrm{~ms}^{-1}(\%)\end{array}$ & $\begin{array}{c}\text { Drag } \\
\text { reduction } \\
\text { at } 80 \mathrm{~ms}^{-1} \\
(\%)\end{array}$ \\
\hline 0 & 0 & 0 & 0 \\
\hline 32 & -1.675 & 0.54 & 5.278 \\
\hline 64 & -2.065 & 0.56 & 5.176 \\
\hline 128 & -1.315 & 0.58 & 5.091 \\
\hline 256 & -0.7915 & 0.59 & 4.989 \\
\hline
\end{tabular}

Fig. 23 shows the skin friction comparison of wavy plate at crest peak and trough with the flat plate. The 
net average deficit in skin friction is $11.23 \%$ for 30 $\mathrm{m} / \mathrm{s}, 14.51 \%$ for $50.1 \mathrm{~m} / \mathrm{s}$ and $17.18 \%$ for $80 \mathrm{~m} / \mathrm{s}$ in the laminar region. The skin friction at the crest peak approaches to the value for the flat plate at $R e_{x}=$ $2.18 \times 10^{6}, 26.5 \%$ before transition $(30 \mathrm{~m} / \mathrm{s}), R e_{x}=$ $1.75 \times 10^{6}, 14.08 \%$ before transition $(50.1 \mathrm{~m} / \mathrm{s})$, and $R e_{x}=2.43 \times 10^{6}, 5.8 \%$ before transition $(80 \mathrm{~m} / \mathrm{s})$. However, Fig. 23 clearly shows that the differences between skin friction values at trough and crest peak dramatically increase as the velocity increases.

The drag values suggest that drag reduction is attained by all wavenumbers at $50.1 \mathrm{~ms}^{-1}$ and $80 \mathrm{~ms}^{-1}$ (Table 7). Drag reduction is the highest at $80 \mathrm{~ms}^{-1}$ with a reduction of $5.278 \%$ for the 32 wave configuration. However, overall drag increased for flow velocity at $30 \mathrm{~m} / \mathrm{s}$, although the transition is delayed.

Table 7 Drag reduction at $30 \mathrm{~ms}^{-1}, 50 \mathrm{~ms}^{-1}$ and $80 \mathrm{~ms}^{-1}$ for $h / \delta=0.004$

\begin{tabular}{|c|c|c|c|}
\hline $\begin{array}{c}\text { Wave } \\
\text { Number } \\
(\mathrm{N})\end{array}$ & $\begin{array}{c}\text { Drag } \\
\text { reduction } \\
\text { at } \\
30 \mathrm{~ms}^{-1} \\
(\%)\end{array}$ & $\begin{array}{c}\text { Drag } \\
\text { reduction at } \\
50.1 \mathrm{~ms}^{-1}(\%)\end{array}$ & $\begin{array}{c}\text { Drag } \\
\text { reduction } \\
\text { at } 80 \mathrm{~ms}^{-1} \\
(\%)\end{array}$ \\
\hline 0 & 0 & 0 & 0 \\
\hline 32 & -1.675 & 0.54 & 5.278 \\
\hline 64 & -2.065 & 0.56 & 5.176 \\
\hline 128 & -1.315 & 0.58 & 5.091 \\
\hline 256 & -0.7915 & 0.59 & 4.989 \\
\hline
\end{tabular}

Thus, the net difference of skin friction between the crest and the trough in laminar region is indicative of delayed transition and drag reduction within the laminar boundary layer.

The values presented herein also indicate that the ideal wavy plate varies with a different flow velocity, and there might be an optimised value. Further research on optimisation should be conducted.

\section{Discussions}

Results presented in subsections 3.1, 3.2 and 3.3 depict the performance of a wavy plate in comparison to the flat plate and each other. The presence of wavy plates with different amplitude results in varied degrees of transition delay and drag reduction. All existing research demonstrates that drag reduction is usually attained within the turbulent boundary layer (Walsh, 1983; Walsh and Lindemann, 1984; Bechert and Hage, 2006; Bixler and Bhushan, 2013). However, the summation of the drag from laminar and the turbulent boundary layer defines the overall drag. Transition delay and lower laminar drag might not result in overall drag reduction as is the case when $h / \delta=0.008$. At $h / \delta=0.003-0.004$, all wavenumbers have a positive impact on drag reduction. However, these sinusoidal wavy features might approach to their limit and all wavenumbers converge to similar levels of transition delay and drag reduction at some points (Table 4 and Table 5). Therefore, an optimal balance is necessary to attain transition delay and overall drag reduction. The low amplitude surface waves having $h / \delta=0.003-0.004$ can be correlated to the micro-features present on the skin of the shark. Shark skin denticles have a height of 2-5 microns(Sharklet Technologies, no date) i.e. $h / \delta=$ $0.002-0.005$

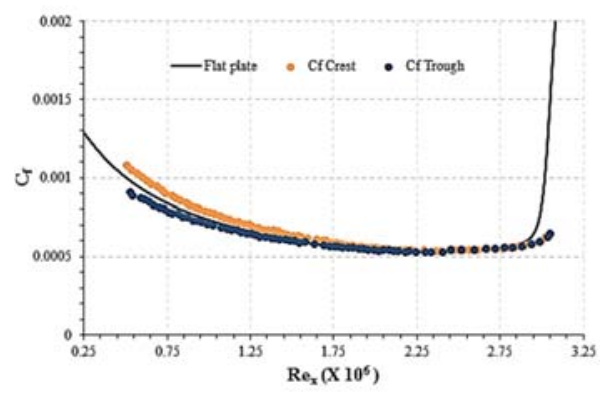

a

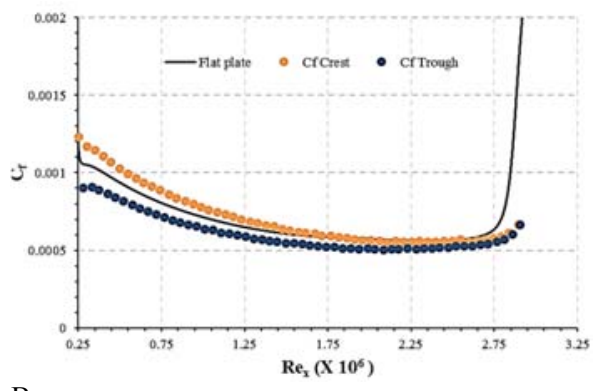

B

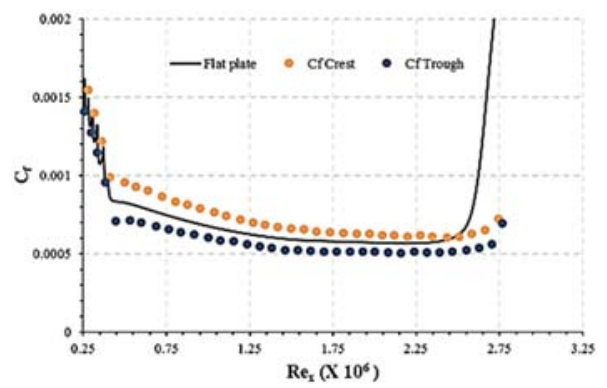

c.

Fig. 23. Skin friction coefficients comparison of wavy plates at crest peak $\&$ trough with flat plate at a) $30 \mathrm{~m} / \mathrm{s}$, b) $50.1 \mathrm{~m} / \mathrm{s}$, and c) $80 \mathrm{~m} / \mathrm{s}$.

On a micro level, observations from the velocity contour (Fig. 10) and the TKE (Fig. 14) indicate that the wavy plate is characterised by fluctuations in the low velocity region and delayed growth of disturbance within the boundary layer. The pressure coefficient (Fig. 13) indicates that the wavy plate depicts a more favourable pressure distribution as compared to the flat plate. The skin friction coefficients (Fig. $16 \mathrm{a}, \mathrm{b}$ ) illustrate that the presence of a wavy plate causes sharp rise in the wall shear stress at the crest and even a sharper decrease in the shear stress in the trough so that the average shear stress at the wall is reduced. The reduction of the shear stress leads to the reduction of disturbances. The delayed growth of disturbance for the wavy plate 
as illustrated by the TKE (Fig. 14) would be the direct indication of the reduction of the shear stress at the wall.

The velocity and TKE distributions for a single wave (Fig. 19 and Fig. 20) indicate a region of low velocity and low turbulence in the trough. The presence of this region of low velocity and low turbulence could possibly result in cushioning of the flow as it enters the trough. Due to the cushioning impact of the flow in the trough, the wall shear stress is greatly reduced. The thickness of this low velocity and low turbulence region in the trough is significantly more than that over the crest. The cushioning of the flow also reduces the hard contact area between the flow and the wall surface, which has been used to explain several phenomena in literature, for example, effects of riblet. The authors believe that the cushioning impact, reduction of the wall shear stress in trough and the reduction in hard contact area play a critical role in improving the flow characteristics and reducing the turbulence on the wavy plate.

Another key insight into the flow mechanism can be provided by the velocity profiles presented for the single wave (Fig. 18 a-e). The presence of the crest results in a largest velocity gradient at the peak (Point C) whereas the trough results in a lowest velocity gradient (Point G). However, these up-and-down of velocity gradient do not transport mass and the momentum, and the velocity gradients at the centreline points of the wave (A, E and I) keep relatively similar. In addition, the velocity and the vorticity magnitude at the centreline points are lower than the corresponding values for the flat plate as the consequences of these up and down motion. The lower vorticity indicates that the presence of the sinusoidal wave results in a reduction in overall disturbance in the flow thereby delaying transition and reducing drag.

A change in the velocity of the incoming flow results in a change in the percentage of transition onset delay (Table 6). At each velocity, a given wavenumber gives the highest transition delay. Drag reduction is observed with an increase in velocity. This might be because the shear stress increase rate at the Crest Rising and the decrease rate at the Crest Falling are related to the flow speed. Thus, the best wavenumber/amplitude to attain transition delay changes with the incoming flow velocity. A possible explanation for this could be the compliant nature of the sharkskin. As the shark swims, it constantly alters its surface profile depending on the incoming flow condition. This enables it to swim efficiently and with minimal drag.

The investigation of surface waves takes inspiration from the shark skin and changes of live shark while swimming in different flow conditions i.e. the velocity etc. result in different wavenumbers and different amplitudes giving different levels of transition delay and drag reduction.

\section{CONCLUSION}

The authors conducted a Transition Delay and Drag Reduction exercise through observing the performance of the shark and simplifying the profile of the shark skin. Based on the hypothesis and the results obtained in this paper, the following conclusions can be drawn:

1. The presence of a wavy plate changes the aerodynamic performance of the plate. When the amplitude is reduced, the effects of wavy features may change from negative to positive. At $h / \delta=0.008$, transition delay is the largest for 32 waves. All three test cases, $h / \delta=$ $0.008, h / \delta=0.004$ and $h / \delta=0.003$ show transition delay and drag reduction for all wavenumbers.

2. The presence of the wavy plate can be correlated to the dermal denticles/ scales on top of another on the surface of the shark skin which have been found to reduce drag. Thus, the hypothesis that the surface waves can enable drag reduction in boundary layers is a valid and justifiable one.

3. The flow structure analysis indicates that at low amplitudes, the skin friction in the trough is lower than the flat plate while the skin friction at the crest is quite similar to the flat plate. The net reduction in skin friction is one of the primary reasons for transition delay and drag reduction.

4. The presence of the wavy plate causes reduction of hard contact surface area between resulting in a cushioning effect.

5. The wavy plate is a key demonstrator of the hypothesis of research presented by the authors. However, optimisation of these wavy features will help in attaining larger drag reduction. Spanwise micro-geometric features have potential in transition delay similar to widely researched streamwise geometric features such as riblets.

6. Balance of transition delay and drag reduction should be sought to maximise the positive effects of the wavy plate.

\section{ACKNOWLEDGEMENTS}

The authors would like to acknowledge that the financial support for this research was provided by a grant from European Union under the SANAD project with Grant Number: 324443.

\section{REFERENCES}

Bacher, E. V. and C. R. Smith (1985). A combined visualization-anemometry study of the turbulent drag reducing mechanisms of triangular microgroove surface modifications. American Institute of Aeronautics and Astronautics, Shear Flow Control Conference, Boulder, CO, Mar. 12-14, 1985. 11 p. USAF-supported research.

Bechert, D. and W. Hage (2006). Drag reduction with riblets in nature and engineering, WIT Transactions on State-of-the-art in Science. 
D. Bhatia et al. / JAFM, Vol. 13, No. 4, pp. 1207-1222, 2020.

Available at: https://www.witpress.com /elibrary/wit-transactions-on-ecology-and-theenvironment/4/18414 (Accessed: 10 July 2017).

Bechert, D. W., M. Bartenwerfer, G. Hoppe and W. E. Reif (1986). Drag reduction mechanisms derived from shark skin. IN: ICAS, Congress, 15th, London, England, September 7-12, 1986, Proceedings. Volume 2 (A86-48976 24-01). New York, American Institute of Aeronautics and Astronautics, Inc., 1986, p. 1044-1068., 2, 1044-1068.

Bechert, D. W., M. Bruse, W. Hage and R. Meyer (2000). Fluid mechanics of biological surfaces and their technological application., Die Naturwissenschaften 87(4), 157-171.

Bixler, G. D. and B. Bhushan (2013). Fluid drag reduction with shark-skin riblet inspired microstructured surfaces. Advanced Functional Materials 23(36), 4507-4528.

Boomsma, A. and F. Sotiropoulos (2016). Direct numerical simulation of sharkskin denticles in turbulent channel flow. Physics of Fluids. AIP Publishing LLC 28(3), 035106.

Bushnell, D. M. (2003). Aircraft drag reduction-a review. Proceedings of the Institution of Mechanical Engineers, Part G: Journal of Aerospace Engineering. SAGE PublicationsSage UK: London, England, 217(1), 1-18.

Choi, H., P. Moin and J. Kim (1993). Direct numerical simulation of turbulent flow over riblets. Journal of Fluid Mechanics. 255(1), 503.

Cossu, C. and L. Brandt (2002). Stabilization of Tollmien-Schlichting waves by finite amplitude optimal streaks in the Blasius boundary layer. Physics of Fluids 14(8), L57-L60.

Dean, B. and B. Bhushan (2010). Shark-skin surfaces for fluid-drag reduction in turbulent flow: a review. Philosophical transactions. Series A, Mathematical, physical, and engineering sciences 368(1929), 4775-4806.

European Comission (2016). European Comission on Reducing Emissions from Aviation, EU Comission Report. Available at: http://ec.europa.eu/clima/policies/transport/avia tion/index_en.htm (Accessed: 18 October 2016).

European Commission (2011). Flightpath 2050 Europe's Vision for Aviation Report of the High Level Group on Aviation Research. Luxembourg. doi: 10.2777/50266.

Gaster, M. (2016). Understanding the Effects of Surface Roughness on the Growth of Disturbances. In 46th AIAA Fluid Dynamics Conference. Reston, Virginia: American Institute of Aeronautics and Astronautics.

Goldstein, D., R. Handler and L. Sirovich (1995). Direct numerical simulation of turbulent flow over a modeled riblet covered surface. Journal of Fluid Mechanics 302, 333.

Gorlé, C., S. Zeoli, M. Emory, J. Larsson and G. Iaccarino (2019). Epistemic uncertainty quantification for Reynolds-averaged NavierStokes modeling of separated flows over streamlined surfaces. Physics of Fluids 31(3), 035101.

Lang, A. W., P. Motta, P. Hidalgo and M. Westcott, (2008). Bristled shark skin: a microgeometry for boundary layer control? Bioinspiration \& biomimetics, 3(4), p. 046005.

Langtry, R. B., F. R.Menter, S. R. Likki, Y. B. Suzen, P. G. Huang and S. Völker (2004).. A Correlation-Based Transition Model Using Local Variables-Part II: Test Cases and Industrial Applications. Journal of Turbomachinery 128(3), 423.

Lessen, M. and S. T. Gangwani (1976). Effect of small amplitude wall waviness upon the stability of the laminar boundary layer. Physics of Fluids. 19(4), 510 .

Lin, Y., S. Raghunathan, B. Raghunathan and S. McIlwain (2011). Prediction of boundary layer transition on a flat plate subject to surface waviness. Proceedings of the Institution of Mechanical Engineers, Part G: Journal of Aerospace Engineering 226(1), 42-54.

Luchini, P., F. Manzo and A. Pozzi (1991). Resistance of a grooved surface to parallel flow and cross-flow. Journal of Fluid Mechanics Digital Archive 228, 87.

Ma, M., J. Lu and G. Tryggvason (2015). Using statistical learning to close two-fluid multiphase flow equations for a simple bubbly system. Physics of Fluids 27(9), 092101.

Mariotti, A., G. Buresti, G. Gaggini and M. V. Salvetti (2017). Separation control and drag reduction for boat-tailed axisymmetric bodies through contoured transverse grooves. Journal of Fluid Mechanics 832, 514-549.

Mariotti, A., G. Buresti and M. V. Salvetti (2014). Control of the turbulent flow in a plane diffuser through optimized contoured cavities. European Journal of Mechanics - B/Fluids 254-265.

Mariotti, A., G. Buresti and M. V. Salvetti (2015). Use of multiple local recirculations to increase the efficiency in diffusers. European Journal of Mechanics, B/Fluids 50, 27-37.

Mariotti, A., G. Buresti and M. V. Salvetti (2019). Separation delay through contoured transverse grooves on a 2D boat-tailed bluff body: Effects on drag reduction and wake flow features. European Journal of Mechanics - B/Fluids. Elsevier Masson 74, 351-362.

Menter, F. R., R. Langtry and S Völker (2005). Transition Modelling for General Purpose CFD Codes. Engineering Turbulence Modelling and Experiments 6, (August), 31-48. 
D. Bhatia et al. / JAFM, Vol. 13, No. 4, pp. 1207-1222, 2020.

Menter, F. R., R. B. Langtry, S. R. Likki, Y. B. Suzen, P. G. Huang and S. Völker (2004). A Correlation-Based Transition Model Using Local Variables - Part I: Model Formulation. Journal of Turbomachinery 128(3), 413.

Oeffner, J. and G. V. Lauder (2012). The hydrodynamic function of shark skin and two biomimetic applications. Journal of Experimental Biology 215(5), 785-795.

Schumacher, J. F., M. L. Carman, T. G. Estes, A. W. Feinberg, L. H. Wilson, M. E. Callow and A. B. Brennan (2007). Engineered antifouling microtopographies-effect of feature size, geometry, and roughness on settlement of zoospores of the green alga Ulva. Biofouling 23(1), 55-62.

Sharklet Technologies, I. (no date) Technology Overview | Sharklet Technologies, Inc. Available at: http://sharklet.com/ourtechnology/technology-overview/ (Accessed: 3 November 2016).

Tomiyama, N. and K. Fukagata (2013). Direct numerical simulation of drag reduction in a turbulent channel flow using spanwise traveling wave-like wall deformation. Physics of Fluids 25(10), 105115.

Tryggvason, G., M. Ma and J. Lu (2016). DNSAssisted modeling of bubbly flows in vertical channels. Nuclear Science and Engineering. 184(3), 312-320.

Walsh, M. J. (1983). Riblets as a Viscous Drag Reduction Technique. AIAA Journal. 21(4), 485-486.

Walsh, M. J. and A. Lindemann (1984). Optimization and application of riblets for turbulent drag reduction. in 22nd Aerospace Sciences Meeting. Reston, Virigina: American Institute of Aeronautics and Astronautics.

Walsh, M. J., W. L. Sellers III and C. B. McGinley, (1989).Riblet drag at flight conditions. Journal of Aircraft 26(6), 570-575.

Wie, Y. S. and M. R. Malik (1998). Effect of Surface Waviness on Transition in Three-Dimensional Boundary-Layer Flow. Computers \& Fluids 27(2), 157-181. 